\title{
The Greenland Mineral Resources Portal - another step forward
}

\author{
Mikael Pedersen, Martin Hansen, Bjørn H. Heincke and Leif Thorning
}

In April 2015, the Geological Survey of Denmark and Greenland (GEUS) together with the Ministry of Mineral Resources in Greenland (MMR) made further progress in the development of web-based facilities to present and disseminate geoscientific information and data. This was presented in a new version of the Greenland Mineral Resources Portal. The portal now provides the users with access to a wealth of geological, geophysical and geochemical data - mostly free of charge (Fig. 1). The primary goal of the portal is to facilitate data searches for exploration companies, but the benefits from the easy access to geoscience data are also open to academic researchers. It is the plan to add several new functionalities to the portal in 2016, and interested users are invited to visit the portal at www. greenmin.gl on a regular basis to follow progress.

\section{Geoscience data - from archive to internet}

GEUS, and its forerunner in Greenland (GGU), had as its core activity the production of geological maps. In the early days, observations and data were documented in field notes and on paper maps, but since the 1980s more and more field data have been recorded digitally. Old archive data are still valuable because in Greenland data acquisition is expensive. Therefore GEUS has worked on digitising and securing historic data and integrating them into modern databases with access through the internet.

GEUS has placed geological data from Greenland on the internet since 2005, when the Greenland Mineral Occurrence Map database (GMOM) was first opened to the public (Thorning et al. 2004). Initially, the GMOM portal expanded geographically year by year, providing access to mineral occurrence data extracted by GEUS from released company reports. In 2011, a new, more ambitious programme was launched as a collaborative project between GEUS and the Bureau of Minerals and Petroleum in Greenland (BMP), the forerunner of MMR. The objective was to compile data and maps from the whole of Greenland into a modern web-platform - the Greenland Mineral Resources Portal - with access to large amounts of
Fig. 1. The interactive map of the Greenland Mineral Resources Portal showing the mineral occurrence layer.





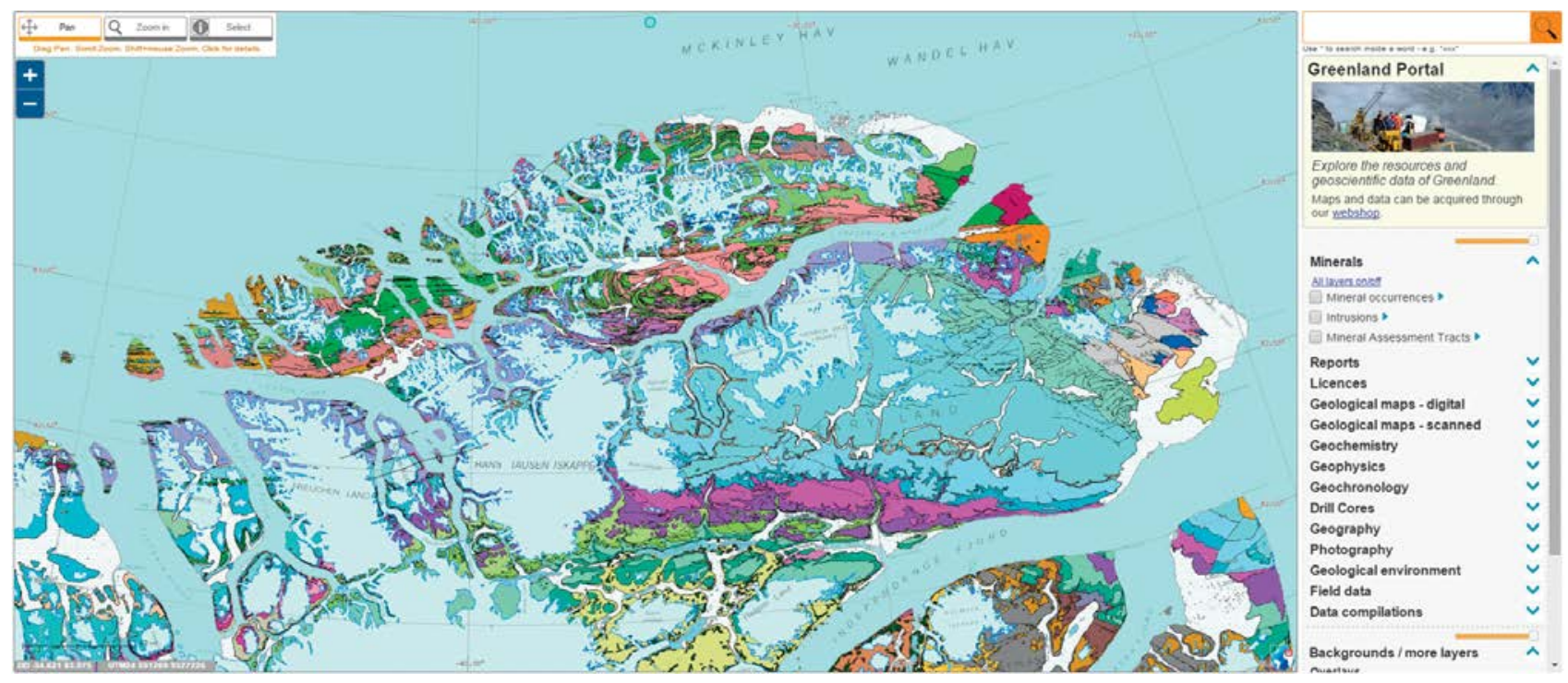

Fig. 2. Northernmost Greenland as it appears in the interactive geological map of Greenland on a scale of 1:500 000.

geoscientific metadata, including full texts of reports made for companies from the DODEX database (Riisager $e t$ al. 2011). The first version of this portal was released in the beginning of 2012, and mainly provided information about the existence of data in different areas, but only to a limited degree the data themselves. However, the need for easy data access for industry was obvious and increasingly the actual data from the large range of GEUS geological databases were added. In 2015 new content and functions were launched to give the users access to download or purchase geochemical and geophysical data and a range of other data types such as geological maps and sample data.

\section{High-quality data}

Geological data are essential for development in the mining sector. Factors such as data quality and access to databases are therefore important parameters when rating a country's attraction to investors as expressed by, for example, the annual survey of mining companies undertaken by the Fraser Institute (Jackson \& Green 2016). In its capacity as a national geological data and knowledge centre, it has for many years been GEUS' fundamental task to develop databases securing valuable data assets. High-quality databases, however, rely not only on skilled developers, but also very much on geoscientific personnel that can continuously ensure the quality of the content. All data have been quality controlled in the central, authoritative databases before being stored and made available in the Greenland Mineral Resources Portal. A few of the data types are described below.
Geophysical data. Geophysical data are in great demand for mineral exploration and the integration of such data into the portal has therefore been a high priority. During the past two decades, GEUS and BMP/MMR have jointly acquired airborne geophysical data in Greenland within the AEM Greenland and Aeromag projects (Rasmussen et al. 2013). Geophysical data are regularly reported by exploration companies to the Greenland authorities as part of their licensing conditions and these are released to the public after a confidentiality period of five years. Prior to 2011, these surveys were handled file by file, but an important achievement of the portal project has been to develop a relational database for the geophysical metadata and data files to make them identifiable for purchase or download via the portal. This work is ongoing, and at present a total of 35 geophysical surveys are available.

Geochemical data. Stream sediment samples have been collected in Greenland since 1971 and geochemical mapping by means of systematically collected and analysed stream sediment samples has been undertaken by GGU/ GEUS since 1975. A geochemical atlas of West and South Greenland was published in 2001 (Steenfelt 2001a) based on 7122 samples analysed for 43 chemical elements. A major task in the preparation of the atlas was the elimination of bias in the analytical data as a prerequisite for the production of the element distribution maps (Steenfelt 1999, 2001b). In 2011, a similar exercise was performed on five elements determined in 2644 stream sediment samples from North Greenland as part of an assessment of the zinc 


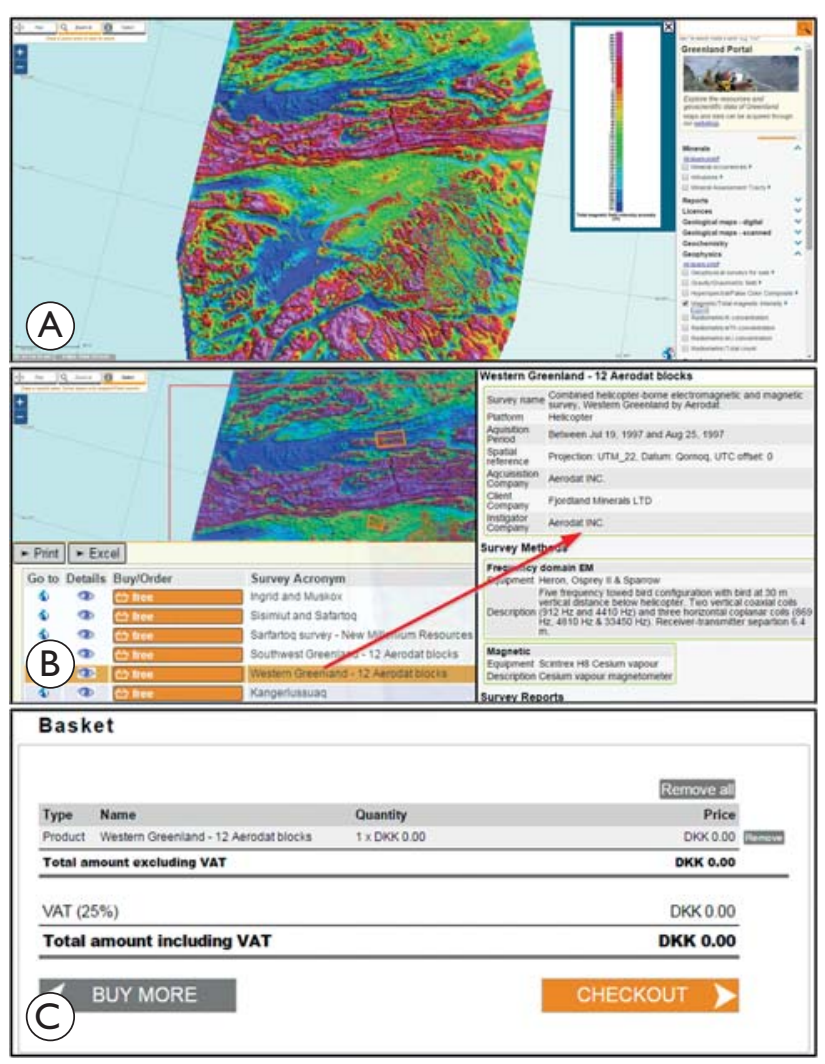

Fig. 3. A: The Total magnetic intensity layer shows where airborne magnetic data are available. B: The layer of Geophysical surveys for sale provides information on the individual geophysical surveys. Intuitive interaction between search results and the map makes it easy to see what geographical areas are part of the individual surveys. Based on metadata and the access to survey reports the user can assess the surveys before purchase or download. C: Individual surveys can be added to the online shopping basket and checked out through the webshop.

potential (Thrane et al. 2011). All geochemical data from these two projects are available in the Greenland Mineral Resources Portal - via the interactive map interface and as free download from the associated webshop. An important part of the ongoing project is the quality control of all geochemical analyses from more than 15000 raw (noncalibrated) stream and scree sediment samples as well as from soil samples and heavy mineral concentrates - all of which are part of the portal.

Geological maps. Geological mapping of Greenland has led to a series of published maps at standard scales. The maps were traditionally produced using engraving techniques, but in 1998 GEUS turned to digital production of paper maps. In recent years the old paper maps have been digitised and made into seamless, geographically referenced products with homogeneous legends, suitable for web applications. A seamless 1:100 000 scale map with a homogenised legend covering 10 map sheets in southern West and South-West Greenland was finalised in 2010 (Keulen et al. 2010), and in 2013 GEUS launched a 1:500 000 scale compilation covering the whole of the ice-free area of Greenland (Pedersen et al. 2013; Fig. 2). Both map layers form important base maps in the Greenland Mineral Resources Portal. The GIS data from the 1:500 000 scale map are available for free download from the webshop.

\section{Targeting the end users}

The development of digitised facilities has been going on for many years during which valuable experience has been gathered. The development has always been demanddriven, but even though exploration companies are a quite well-defined user group, various requirements need to be addressed. The focus is not only to provide access to as much reliable data as possible, but also to create online facilities for screening and evaluating the data. Therefore, the development of the portal is based on cases that describe scenarios for a specific user (e.g. a small-scale miner) expecting a certain result. A couple of scenarios are given in the following to demonstrate the flexibility and potential of the Greenland Mineral Resources Portal.

Scenario 1: Discovery and download of geophysical data in a given area. Many exploration geologists are interested in geophysical data from a specific area. In the interactive map of the Greenland Mineral Resources Portal it is easy to zoom in on an area and see the available aeromagnetic data by switching on the Total magnetic intensity layer (Fig. 3A).

By adding the Geophysical surveys for sale layer to the map, information about the individual geophysical surveys available in the area, including metadata and reports, can be inspected (Fig. 3B).

The user buys data by adding the relevant surveys to the shopping basket, after which they can be checked out from the webshop (Fig. 3C). Many geophysical datasets are available free of charge, and others can be paid by credit card and subsequently downloaded.

Scenario 2: Search for stream sediment samples with high gold content. In the interactive map users can search through each of the geochemical datasets for samples with an element content larger than a value defined by the user. This makes it possible for the user to easily assess areas of interest 


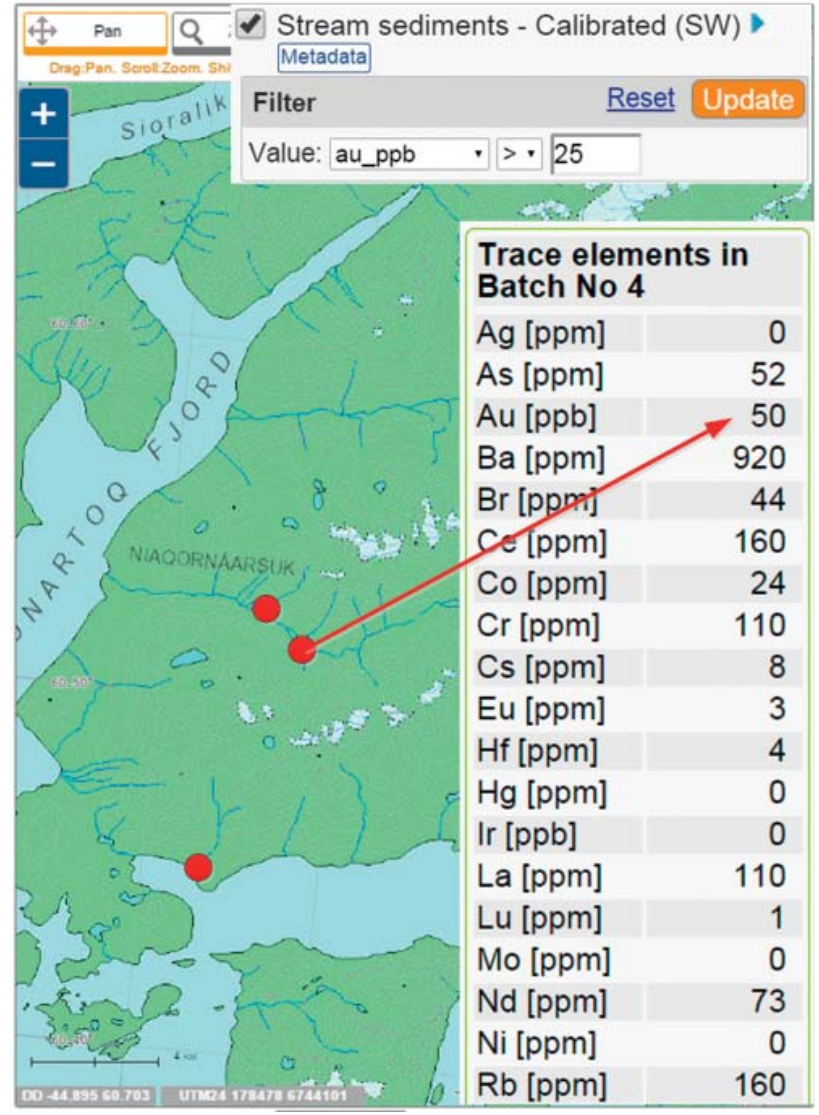

Fig. 4. A search for samples with more than $25 \mathrm{ppb}$ gold in the calibrated stream sediment dataset from South-West Greenland. All analytical results for a given sample can be seen on the screen, and the entire (or geographic subsets) of the dataset can be downloaded from the webshop.

without advanced GIS software. In Fig. 4 the result of a search for samples with more than 25 ppb gold is shown for an area in South-West Greenland. The locations of stream sediment samples that fulfil that criterion are displayed on a map, and more information about the samples can be seen by clicking the red dots.

More advanced users can download all of the geochemical datasets (or geographic subsets) free of charge from the webshop for further analyses using their own software.

\section{Looking ahead}

The development of the Greenland Mineral Resources Portal is ongoing. More and more data types are added, and the existing datasets are continuously supplemented. In 2016, it is the plan to add a geochronological database and a drill-core directory and future plans include integration of satellite imagery, additional aerial photographic collections, more geochemical and geophysical data and digital elevation models. The user-friendly functions of the portal interface will be further improved and refined along the way, and users are always encouraged to give feed-back to GEUS and the Ministry of Mineral Resources for continuous improvements.

\section{Acknowledgements}

The Ministry of Mineral Resources under the Government of Greenland is thanked for financial support for the development of the Greenland Mineral Resources Portal. The authors also wish to thank the team from the Department of Petrology and Economic Geology as well as the Geological Datacentre at GEUS, who have actively worked to make the Greenland Mineral Resources Portal a success.

\section{References}

Jackson, T. \& Green, K.P. 2016: Fraser Institute annual survey of mining companies 2015, 86 pp. Vancouver: Fraser Institute.

Keulen, N.T., Kokfelt, T.F. \& Scherstén, A. 2010: Notes on the common legend to the 1:100 000 digital geological map of southern West and South-West Greenland, 61० $30^{\prime}-64^{\circ} \mathrm{N}$. Danmarks og Grønlands Geologiske Undersøgelse Rapport 2010/119, 41 pp.

Pedersen, M., Weng, W.L., Keulen, N.T. \& Kokfelt, T.F. 2013: A new seamless digital 1:500 000 geological map of Greenland. Geological Survey of Denmark and Greenland Bulletin 28, 65-68.

Rasmussen, T.M., Thorning, L., Riisager, P. \& Tukiainen, T. 2013: Airborne geophysical data from Greenland. Geology and Ore, Exploration and Mining in Greenland 22, 12 pp.

Riisager, P., Pedersen, M., Jørgensen, M.S., Schjøth, F. \& Thorning, L. 2011: DODEX - Geoscience documents and data for exploration in Greenland. Geological Survey of Denmark and Greenland Bulletin 23, 77-80.

Steenfelt, A. 1999: Compilation of data sets for a geochemical atlas of West and South Greenland based on stream sediment surveys 1977 to1997. Danmarks og Grønlands Geologiske Undersøgelse Rapport 1999/41, 33 pp.

Steenfelt, A. 2001a: Geochemical atlas of Greenland - West and South Greenland. Danmarks og Grønlands Geologiske Undersøgelse Rapport 2001/46, $39 \mathrm{pp}$.

Steenfelt, A. 2001b: Calibration of stream sediment data from West and South Greenland. A supplement to GEUS Report 1999/41. Danmarks og Grønlands Geologiske Undersøgelse Rapport 2001/47, 43 pp.

Thorning, L., Christensen, L., Schjøth, F. \& Stendal, H. 2004: Greenland Mineral Occurrence Map. Status report for the development of a prototype for the Internet, January 2004. Danmarks og Grønlands Geologiske Undersøgelse Rapport 2004/28, 52 pp.

Thrane, K., Steenfelt, A. \& Kalvig, P. 2011: Zinc potential in North Greenland. Danmarks og Grønlands Geologiske Undersøgelse Rapport 2011/143, 64 pp.

\footnotetext{
Authors' address

Geological Survey of Denmark and Greenland), Øster Voldgade 10, DK-1350 Copenhagen K, Denmark, E-mail: mp@geus.dk
} 